\title{
Museu do Amanhã: uma investigação tátil com o olhar ás cegas de quem vê
}

\section{Museum of Tomorrow: a touch investigation with a blind view of those who see}

1 Elias dos Santos Silva Júnior eliasjk@gmail.com

1 Ana Nogueira Braga

1 Sergio Rodrigues Bahia

1 Sérgio Crespo C. da Silva Pinto

1 Ruth Maria Mariani Braz

\section{RESUMO}

A pesquisa analisa a acessibilidade, apresentando os desafios enfrentados pelas pessoas com deficiência visual ao se locomoverem pelo ambiente da exposição principal no Museu do Amanhã. O visitante é convidado a conhecer as suas cinco grandes áreas temáticas: “Cosmos, Terra, Antropoceno, Amanhãs e Nós”. As amostras analisadas foram os recursos acessíveis destinados ao visitante com deficiência visual em sua interação com as atrações do museu. A norma da ABNT NBR 16537/2016 que estabelece os padrões de sinalização tátil no piso e define as diretrizes para a elaboração de projetos e instalações, ela foi utilizada como referência para avaliar a sinalização tátil do percurso de visitação. O áudio guia foi avaliado como Tecnologia Assistiva destinada a esses visitantes. Os recursos metodológicos utilizados foram a revisão de literatura, a pesquisa de campo do tipo observação participante e não participante. Os dados apresentados foram de ordem qualitativa e primária, basicamente, relacionados com as especificações recomendadas pela norma brasileira e a capacidade do áudio guia em contribuir com a autonomia e mobilidade das pessoas com deficiência visual. O resultado da pesquisa relatou a não observância das recomendações normativas em relação à sinalização tátil, algumas inconsistências no áudio guia e diversas barreiras físicas posicionadas sobre a sinalização tátil. O Museu do Amanhã possui como premissa a acessibilidade física em seus espaços e na relação de seus colaboradores para com os visitantes. Entretanto, a pesquisa aponta que o museu do amanhã necessita observar e se adequar à norma da ABNT NBR 16537/2016, treinar os seus colaboradores sobre os recursos acessíveis e reestruturar o áudio guia para que se torne uma Tecnologia Assistiva eficiente e eficaz para conseguir atingir a meta da acessibilidade.

Palavras-chave: Museu do Amanhã. Deficiência Visual. Piso Tátil. Tecnologia Assistiva. Acessibilidade.

\section{ABSTRACT}

The research analyzes the accessibility, presenting the challenges faced by people with visual impairment when traveling around the main exhibition environment in the Museum of Tomorrow. The visitor is invited to know his five major thematic areas: "Cosmos, Earth, Anthropocene, Tomorrow and We". The analyzed samples were the accessible resources intended for visually impaired visitors in their interaction with museum attractions. The standard of ABNT NBR 16537/2016 that establishes tactile signaling patterns on the floor and defines the guidelines for the elaboration of projects and facilities was used as reference to evaluate the tactile signaling of the visitation route. The audio guide was evaluated as Assistive Technology aimed at these visitors. The methodological resources used were literature review, participatory and non- 
-participant observation field research. The data presented were qualitative and primary, basically related to the specifications recommended by the Brazilian standard and the audio guide's ability to contribute to the autonomy and mobility of people with visual impairment. The results of the study reported a lack of observance of the normative recommendations regarding tactile signaling, some inconsistencies in the audio guide and several physical barriers placed on tactile signaling. The Museum of Tomorrow has as a premise the physical accessibility in its spaces and in the relationship of its collaborators with the visitors. However, the research points out that the museum of tomorrow needs to observe and conform to the norm of ABNT NBR 16537/2016, to train its collaborators on the accessible resources and to restructure the audio guide to become an Assistive Technology efficient and effective to achieve the goal of accessibility.

Keywords: Museum of Tomorrow. Visual Deficiency. Tactile floor. Assistive technology. Accessibility.

\section{INTRODUÇÃO}

O Museu do Amanhã afirma que possui a acessibilidade como premissa em sua construção física e em sua interação entre a equipe do museu e seus visitantes. Seu espaço físico dispõe de pisos e maquetes táteis, rampas, cadeiras de rodas, elevadores, fraldários, banheiros adaptados e sinalização universal (MUSEU, 2017). De acordo com Godinho:

Acessibilidade consiste na facilidade de acesso e de uso de ambientes, produtos e serviços por qualquer pessoa e em diferentes contextos. Envolve o Design Inclusivo, oferta de um leque variado de produtos e serviços que cubram as necessidades de diferentes populações (incluindo produtos e serviços de apoio), adaptação, meios alternativos de informação, comunicação, mobilidade e manipulação. (GODINHO, 2010, p. 09)

Dessa forma, a acessibilidade não deve ser uma virtude presente somente no Museu do Amanhã, mas em todos os espaços públicos, pois é dever do estado e de todos garantirem o acesso igualitário aos cidadãos e na forma legal, como descreve a constituição federal de 1988, artigo $5^{\circ}$, todos nós somos iguais perante a lei sem a distinção de qualquer natureza (BRASIL, 1988) e no decreto federal n 5.296/04, no qual expõe critérios básicos de acessibilidade nas edificações públicas e de uso público em seu interior e na comunicação em todas as suas dependências e serviços. O Desenho Universal garante que os espaços poderão ser usados por todos, não importando as barreiras decorrentes de suas deficiências (BRASIL, 2004).

A deficiência deixou de ser uma característica da pessoa com deficiência e passou a ser o resultado da falta de acessibilidade destinada ao ambiente. A Lei brasileira de Inclusão (LBI) institui que a deficiência está no meio e não nas pessoas. A pessoa com deficiência tem assegurado o direito ao exercício de sua capacidade legal em igualdade com as demais pessoas sem qualquer restrição (BRASIL, 2015).

Nesse sentido, Bersch (2013) sinaliza que a Tecnologia Assistiva (TA) visa caracterizar todo o conjunto de recursos e serviços que contribuam para proporcionar ou ampliar habilidades funcionais de pessoas com deficiências na intenção de promover a sua independência e inclusão.

No Brasil, temos normas para os mais variados segmentos de produtos e instalações, sejam residenciais, prediais, urbanas e outras. A Associação Brasileira de Normas Técnicas (ABNT) em sua Norma Brasileira NBR 16537/2016 define como devemos promover a acessibilidade através da sinalização tátil no piso e dita as diretrizes para a elaboração de projetos e instalações. A sinalização tátil no piso é um recurso complementar que se destina prover a segurança, orientação e mobilidade a todos, principalmente as pessoas com deficiência visual ou surdo-cegueira (ABNT, 2016).

Segundo Baptista (2006), não basta tornar os ambientes acessíveis, é preciso que as pessoas tornem-se acessíveis e inclusivas, tendo como visão a premissa de que todas as pessoas em uma sociedade democrática possuem 
direitos e deveres e que ninguém deve ser excluído, por qualquer que seja a razão, nesse prisma a acessibilidade é um direito de todos.

Nesse contexto, Silva Júnior (2018) desenvolveu uma pesquisa de um Mapa Tátil computacional embarcado como Tecnologia Assistiva destinado ao ensino dos alunos com deficiência visual. Na construção, no desenvolvimento e no aprimoramento dessas tecnologias ficou comprovado ser fundamental a opinião de profissionais que atuem na deficiência visual (professores, técnicos e outros) e das pessoas com deficiência visual, na intenção de construir juntos, avaliar e validar esses materiais, tornando-os mais eficientes e eficazes.

Portanto, o artigo analisa uma das premissas do Museu do Amanhã no foco da acessibilidade disponível às pessoas com deficiência visual. O processo de avaliação será conduzido pela verificação da observância da norma ABNT NBR 16537/2016 e na escuta atenciosa e funcional do áudio guia disponibilizado como Tecnologia Assistiva (TA).

\section{METODOLOGIA}

A metodologia utilizada na pesquisa foi a revisão de literatura que abordaram a temática. A pesquisa de campo do tipo observação participante contribuiu para a investigação da sinalização tátil do museu, somada ao uso e análise do áudio guia como Tecnologia Assistiva (TA). Também nos auxiliou nesse processo, a pesquisa de campo de observação não participante na obtenção de dados sobre os visitantes com deficiência visual no momento de sua interação com o ambiente do museu e na observação comportamental dos funcionários em relação ao público e nas atitudes destinadas a manutenção dos recursos de acessibilidade do museu.

O elemento chave foi a sinalização tátil no piso, instalada no Museu do Amanhã, em toda a sua extensão e disposição, conforme observa a norma ABNT NBR 16537/2016, através da visitação do museu que ocorreu no dia 08/12/2016 às $13 \mathrm{~h} 00 \mathrm{~min}$. Avaliamos a qualidade do áudio guia como Tecnologia Assistiva apontando as suas funcionalidades como uma ferramenta que possa contribuir para assegurar a qualidade da acessibilidade local, a segurança do visitante com deficiência visual em transitar pelo espaço e o seu entendimento por parte dos conteúdos propostos pelo museu.

\section{A INVESTIGAÇÃO NO MUSEU DO AMANHÃ}

O Museu do Amanhã é uma obra arquitetônica que a Prefeitura do Rio de Janeiro concebeu ao povo carioca e aos seus visitantes, sendo realizada em conjunto com parcerias público-privadas, intermediada pela Financiadora de Estudos e Projetos (FINEP) e justificada pela Lei Federal de Incentivo à Cultura. A sua gestão é de responsabilidade do Instituto de Desenvolvimento de Gestão (IDG) (MUSEU, 2017).

A sua proposta é ser um museu de ciências diferente em sua arquitetura, sendo erguido sobre os pilares éticos da sustentabilidade e convivência. Seu objetivo é explorar a época de profundas transformações em que vivemos e os possíveis caminhos para os próximos 50 anos. O amanhã não é uma data no calendário, não é um lugar aonde vamos chegar. É uma construção da qual participamos todos, como pessoas, cidadãos, membros da espécie humana (MUSEU, 2017).

Na figura 01, ilustramos o espaço investigado, permitindo ao leitor um acompanhamento espacial mais amplo do museu. 
Figura 01 - Planta do espaço da Exposição Principal.

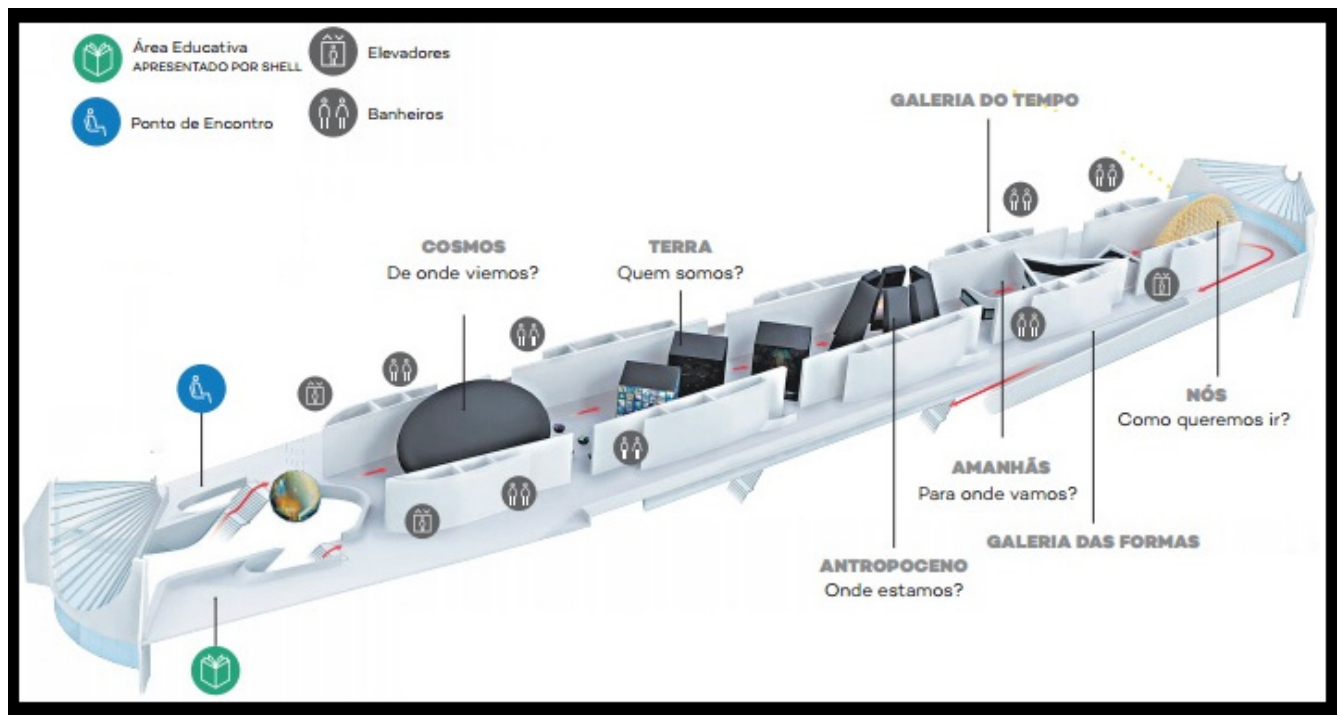

Fonte: Imagem adaptada do site (MUSEU, 2017).

A exposição principal é composta pelo trajeto sequencial do COSMOS, da TERRA, do ANTROPOCENO, das AMANHÃS, da GALERIA DO TEMPO, da GALERIA DAS FORMAS e de NÓS (MUSEU, 2017).

Na figura 02, apresentamos a entrada do Museu do Amanhã e como foi posicionada a sinalização tátil instalada sobre o piso.

Figura 02 - Entrada principal do museu e acesso à recepção.

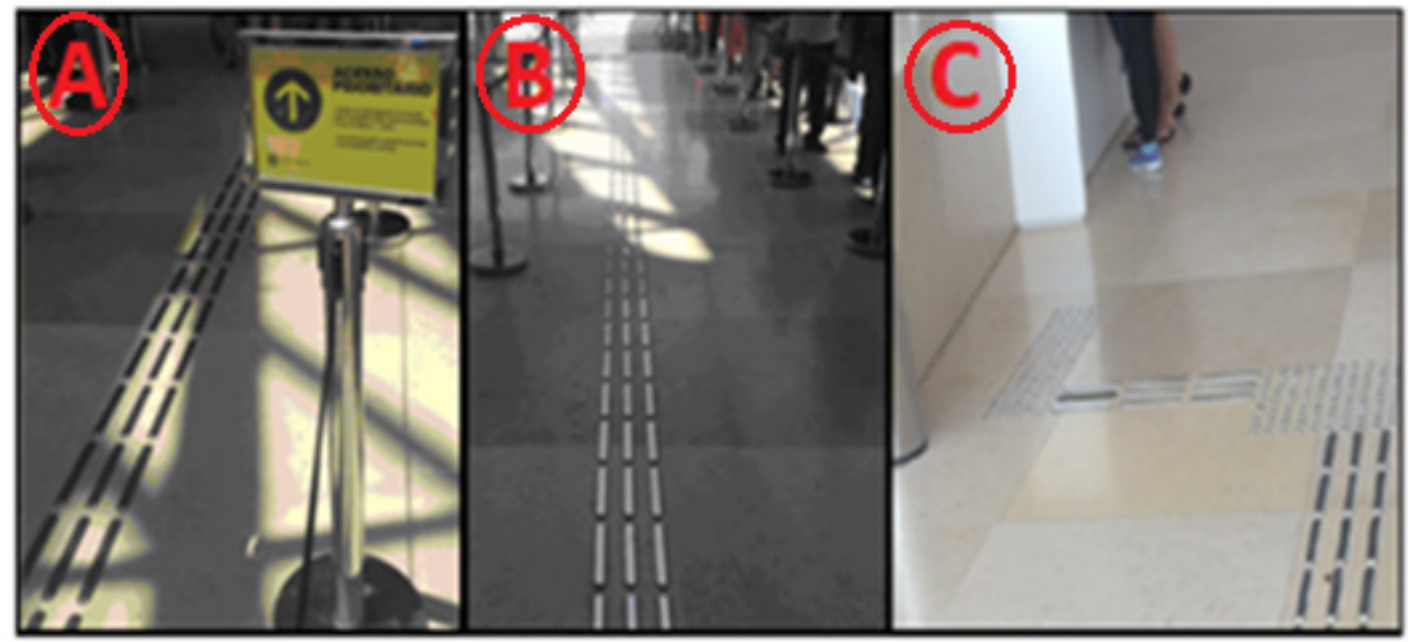

Fonte: Dos autores, 2019.

Logo na entrada, existe um acesso prioritário para as pessoas com deficiência, idosos e gestantes (figura 02A). Encontramos uma sinalização tátil sobre o piso construída com materiais de ótima qualidade que se estende desde a entrada do museu até o atendimento na recepção (figura 02).

No segmento, a norma da ABNT NBR 16537/2016 foi atendida parcialmente, estando conforme o contraste de cor da sinalização com a cor do solo (figura 2), a forma e largura da sinalização tátil direcional (figura 2 em comparação com as ilustrações da figura 3A) e na mudança de direção em $90^{\circ}$ (figura 2C conforme a figura 3B). 
Figura 03 - Referência da Sinalização Tátil utilizada na entrada do museu.

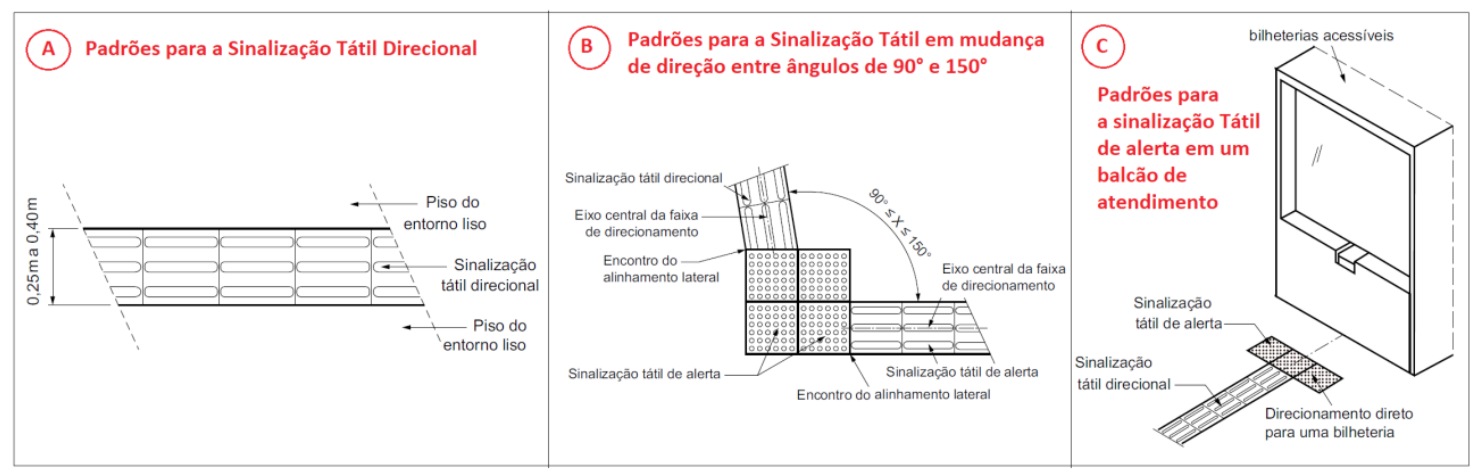

Fonte: Figuras adaptadas da norma ABNT NBR 16537/2016.

O segmento não conforme foi identificado na sinalização tátil de alerta junto ao balcão de informações (figura 2C) que deveria ter sido disposto como apresentado na figura 3C. O encontro da sinalização Tátil direcional junto à sinalização tátil de alerta (figura 2C) possui a configuração em que a norma destina ao acesso a elevadores, induzindo à pessoa com deficiência visual a buscar pela "Botoeira” do elevador à sua esquerda, como ilustrado na figura 4.

Figura 04 - Sinalização Tátil utilizada em elevadores.

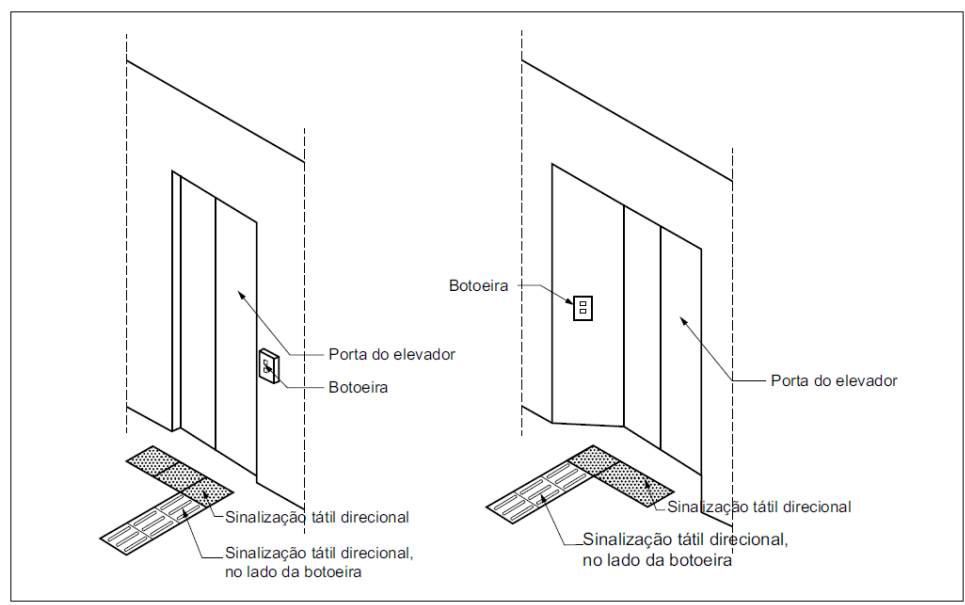

Fonte: Figura adaptada da norma ABNT NBR 16537/2016.

O visitante com deficiência visual (figura 05A) ao ser identificado pela recepção recebe um tablet e um fone de ouvido como Tecnologia Assistiva (figura 05B) que executa o sistema de áudio guia do museu. 
Figura 05 - Visitante deficiente visual utilizando a TA do museu.

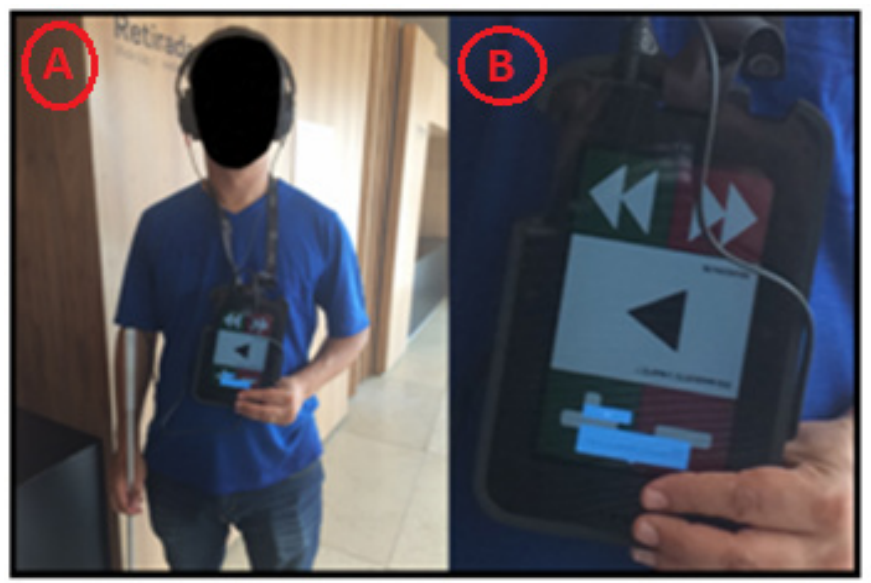

Fonte: Dos autores, 2019.

Ao executar a faixa 01 nessa Tecnologia Assistiva, o áudio guia explicou o funcionamento dos seus controles e na próxima faixa, direcionou o visitante para o elevador que provê acesso ao segundo piso, onde localiza-se a exposição principal do Museu do Amanhã.

No acesso ao segundo piso e na saída do elevador, reparamos a inexistência da sinalização tátil recomendada pela norma (figura 04). Entretanto, o áudio guia orienta o visitante com deficiente visual a guiar-se tateando a parede, à esquerda, ao sair do elevador até localizar a sinalização tátil de alerta a poucos passos, neste trecho, não foi observada a norma da ABNT NBR 16537/2016, conforme apresentado na figura 06.

Ainda Observando a figura 06, encontramos barreiras físicas alocadas sobre a sinalização tátil de alerta o que poderia ocasionar danos físicos ao visitante com deficiência visual. Em conformidade com a norma, a sinalização deveria ser uma combinação do que apresentamos na figura 04 (saída do elevador), adicionada a uma mudança de direção em $90^{\circ}$ (figura 03B) e no meio do corredor, paralelo à parede à esquerda do elevador (figura 06B), a instalação de uma sinalização tátil direcional (figura 3A) até a próxima mudança de direção que ocorrerá à esquerda no ângulo de $90^{\circ}$ (figura 06A).

Figura 06 - Barreiras físicas localizadas na saída do elevador no $2^{\circ}$ piso.

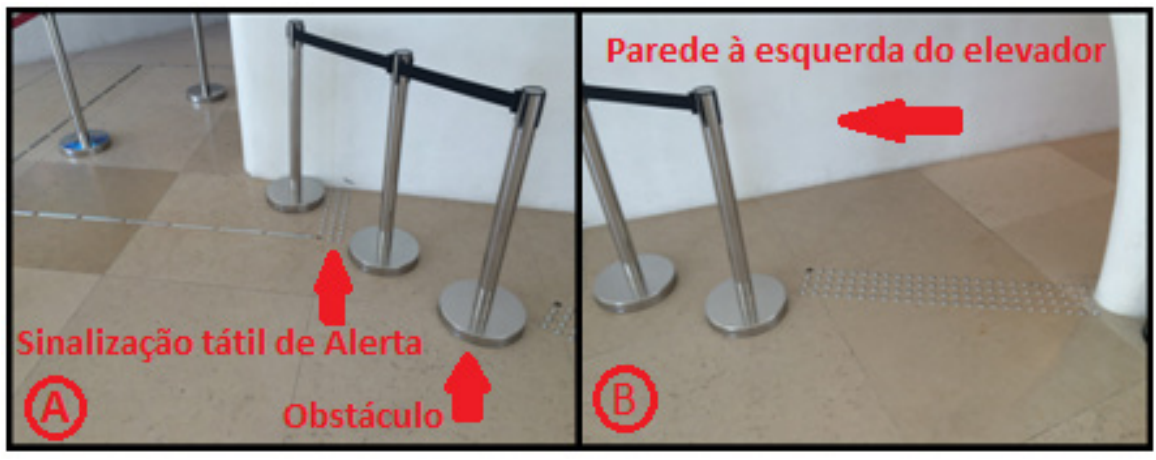

Fonte: Dos autores, 2019.

A sinalização tátil direcional instalada sobre o piso e disposto por todo o segundo andar foi constituída de uma única linha tátil (figuras 06A, 08A, 08B, 9A, 9B, 9C e 11) o que não observa a norma ABNT NBR 
16537/2016 em sua largura e formato que deveriam ser de $0,25 \mathrm{~m}$ a $0,40 \mathrm{~m}$ em se tratando de um piso liso, como apresentado na figura 03A.

Além dessas não conformidades, observamos que em todas as mudanças de direção em $90^{\circ}$ (figuras 06A, 8B e 9A) e no encontro das três faixas direcionais (figura 9C), instaladas no trajeto do segundo andar, também, não observaram a norma da $\mathrm{ABNT}$, pois na mudança de direção a norma prevê uma sinalização de alerta contendo o dobro da largura da sinalização tátil direcional, conforme disposto na ilustração da figura 3B e num encontro de três faixas direcionais a norma define que a sinalização tátil deve possuir um formato de alerta com dimensão equivalente ao triplo da largura da sinalização tátil direcional (figura 7A).

Nos casos em que ocorram obstáculos no ambiente, eles devem ser posicionados a pelo menos um metro da sinalização tátil direcional, conforme representado na figura 7B.

\section{Figura 07 - Sinalização tátil no encontro de três faixas direcionais e distância para obstáculos da sinalização tátil direcional.}

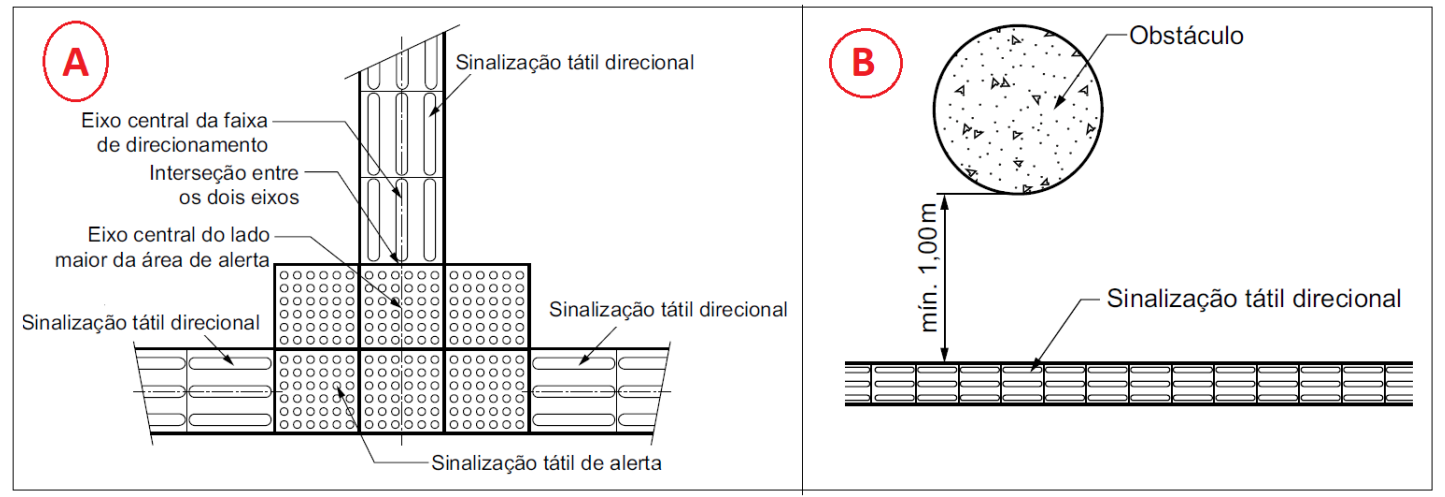

Fonte: Figuras adaptadas da norma ABNT NBR 16537/2016.

No acesso à entrada do “COSMOS - De onde viemos?”, observamos mais algumas incoerências normativas, pois nos deparamos com inúmeras barreias físicas (figura 08) que foram instaladas pelos colaboradores do museu para organizar o direcionamento das filas em direção à entrada do "COSMOS".

Figura 08 - Barreiras sobre a sinalização na entrada do "COSMOS”.

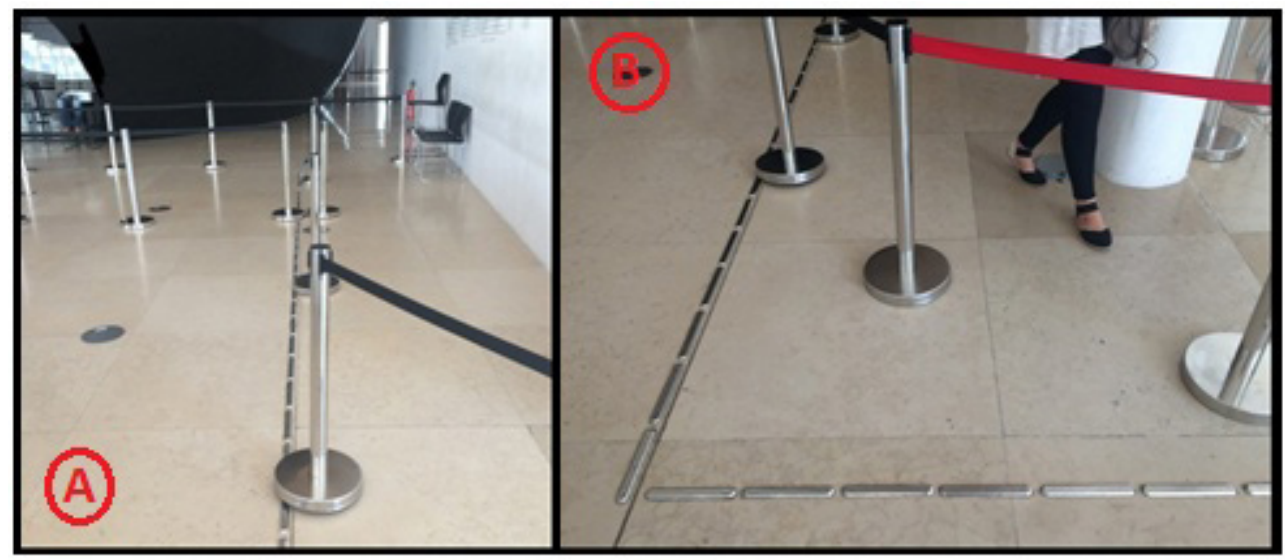

Fonte: Dos autores, 2019. 
No “COSMOS” foi exibido um filme, cujo visitante com deficiência visual pode acompanhá-lo por meio do áudio guia, simultaneamente, com a trilha sonora exibida e ao término da atividade todos são convidados a saírem do "COSMOS” (figura 09A) e nos deparamos com uma placa informando "Somente Saída”, praticamente sobre o piso tátil, o que poderia acarretar um dano ao visitante com deficiência visual e contraria a norma como ilustrado na figura 07B.

Figura 09 - Placa sobre a sinalização, sinalização tátil de alerta errôneo e encontro de três faixas direcionais ortogonais incorretas.

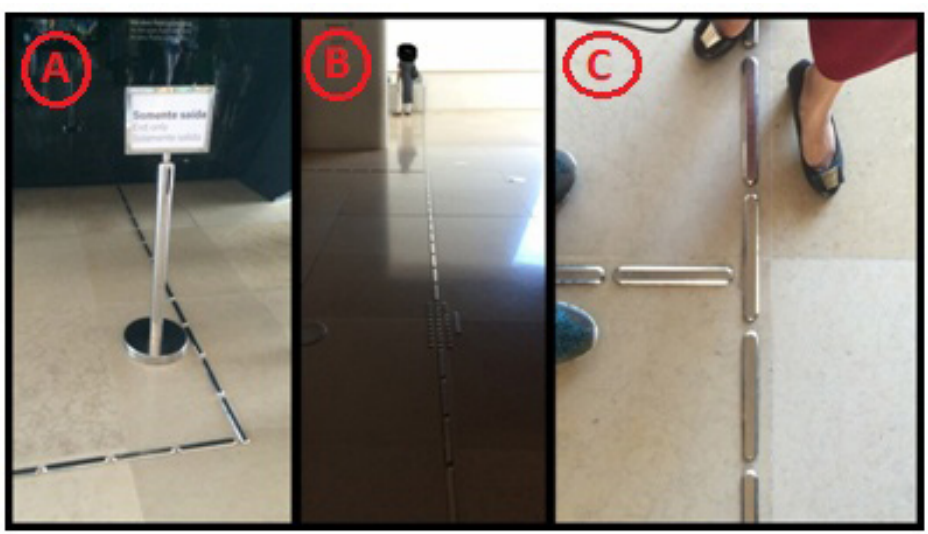

Fonte: Dos autores, 2019.

O áudio guia sinaliza ao visitante com deficiência visual sobre uma sinalização de alerta (figura 09B) e que logo após uma determinada contagem de passos, seria possível encontrar uma rota a sua frente e outra a sua esquerda (figura 09C). Para estar conforme com a norma a sinalização tátil no encontro de três faixas deveria ser representada conforme a figura 07A e cada uma das três sinalizações táteis direcionais deveriam seguir o padrão conforme a ilustração da figura 03A.

Durante a investigação no Museu do Amanhã, observamos um adolescente com deficiência visual que conseguiu ler corretamente a escrita em Braile (figura 10B), reproduzindo-a em voz alta todas as informações, demonstrando ter assimilado toda a dinâmica proposta pela maquete tátil representada pela figura 10A.

Figura 10 - Maquete tátil da Bahia de Guanabara e da localização do Museu do Amanhã. Legenda tátil da localização do museu em Braille.

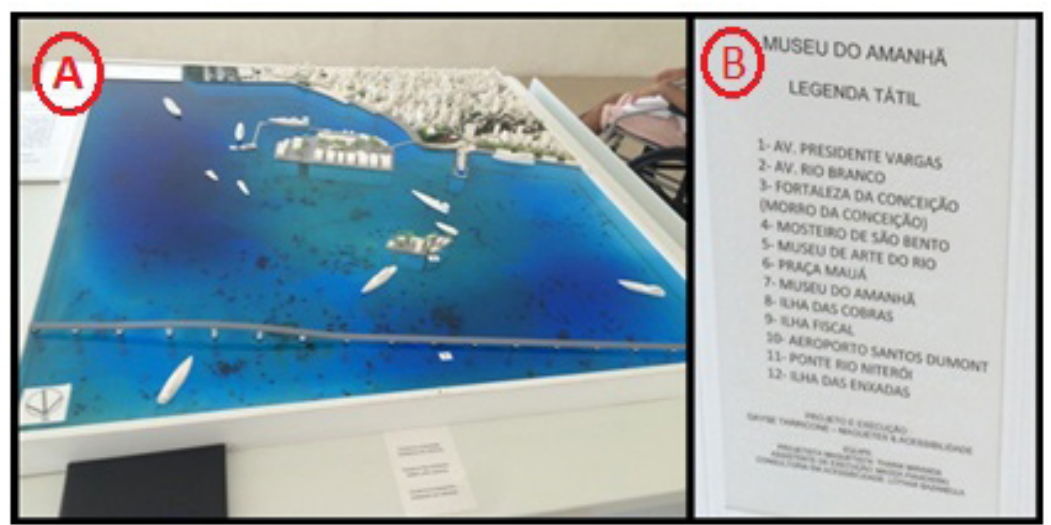

Fonte: fotos produzidas pelos autores. 
As maquetes táteis do Museu do Amanhã foram construídas com materiais de ótima qualidade, rica em detalhes e numa primeira análise, apresentaram ser acessíveis aos visitantes com deficiência visual (figura 10A).

Após a passagem pelas maquetes o áudio guia nos direciona para a última atração do Museu do Amanhã que é a ala do “NÓS - Como queremos ir?”, conforme lustramos na figura 11.

\section{Figura 11 - Foto a ala NÓS - Como queremos ir?}

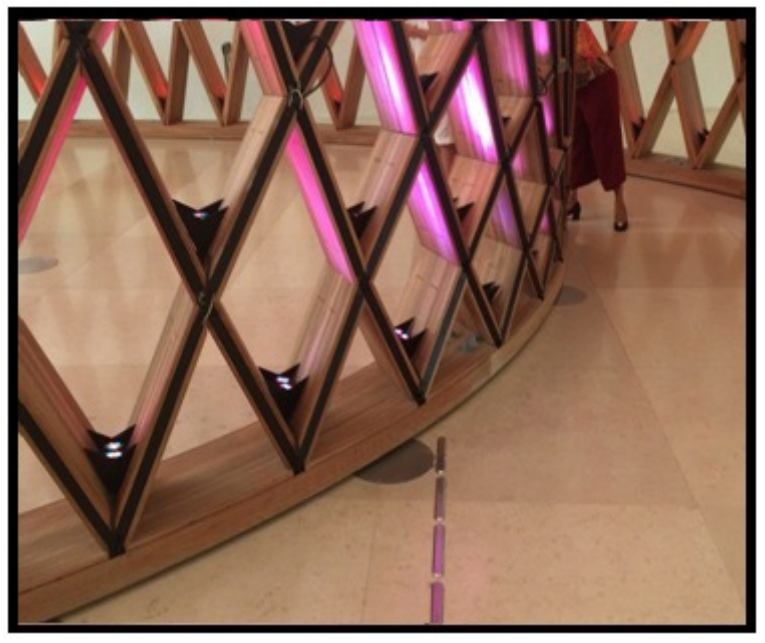

Fonte: foto produzida pelos autores.

No trajeto do "NÓS”, apontamos irregularidades na sinalização tátil direcional (figura 11) que segundo a normativa, além de não possuir a largura conforme a norma (figura 3A), direciona o visitante para uma grande barreia de madeira (figura 11), podendo ocasionar um acidente por não existir uma sinalização tátil de alerta.

Neste ponto, o visitante com deficiência visual é instruído pelo áudio guia a seguir o piso tátil direcional até que ele encontre uma estrutura de madeira (figura 11). O guia informa que a estrutura é iluminada e alerta ao visitante para que tenha bastante cuidado ao tateá-la, pois as lâmpadas podem estar aquecidas.

Depois da visitação da escultura na ala "NÓS", o áudio guia direciona o visitante com deficiência visual até uma grande parede localizada à frente (figura 12A). Em seguida, o visitante deve tateá-la à sua esquerda até encontrar um corrimão que irá auxiliá-lo na descida por uma longa rampa em direção ao $1^{\circ}$ piso do museu. Encontramos uma lixeira obstruindo o acesso ao corrimão, o que consta como não conformidade à norma (figura 07B), sendo mais um objeto na função de uma barreira física. 
Figura 12 - Inicio da rampa de acesso ao $1^{\circ}$ piso e final do percurso.

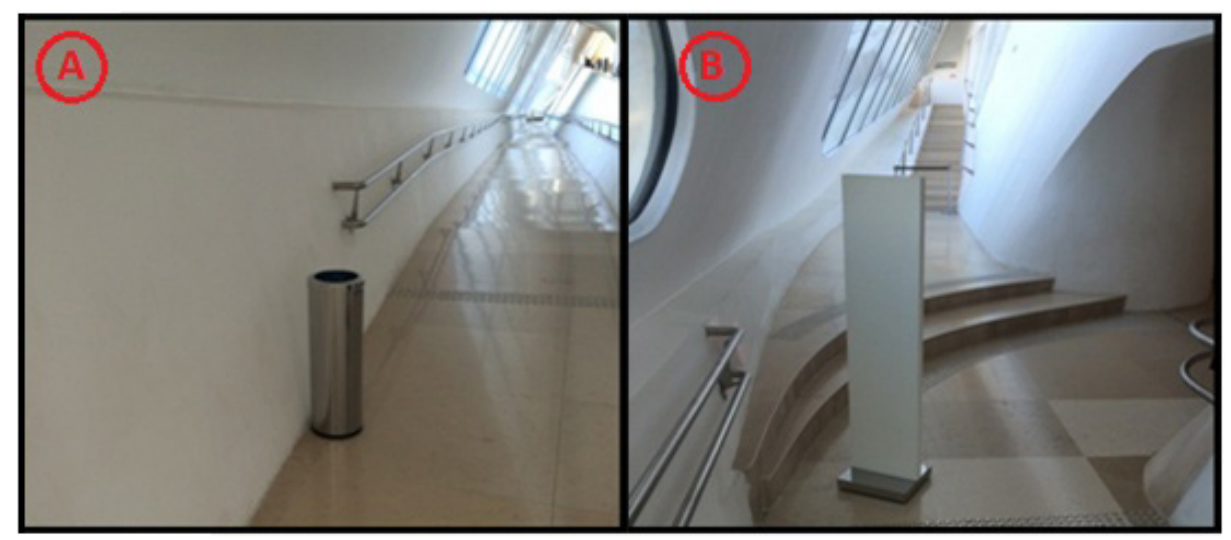

Fonte: foto produzida pelos autores.

Na descida da rampa, o visitante deve guiar-se pelo corrimão e o áudio guia promove uma noção de distância, pois informa a contagem de passos necessários para transpor o trajeto. Ao final na rampa e do corrimão, encontramos mais uma barreira e desta vez uma enorme placa de informações que poderia por em riso a integridade física do visitante (figura 12B).

No trecho final de descida, o áudio guia orienta o uso da bengala para que ele consiga fazer o contorno lateral nos degraus sem sofrer uma queda ocasionada por um esbarrão (Figura 12B), permitindo o seu acesso ao primeiro piso do Museu do Amanhã, a devolução da Tecnologia Assistiva à recepção e o término da visitação ao espaço.

\section{CONSIDERAÇÕES FINAIS}

O Museu do Amanhã é um investimento arquitetônico e cultural dos cariocas, de seus visitantes, dos brasileiros e dos cidadãos do mundo inteiro, sendo planejado, construído e, atualmente, administrado com recursos públicos e de iniciativa privada, tendo como uma de suas premissas, ser acessível a todos.

As pessoas com deficiência possuem os seus direitos garantidos por lei, o pleno exercício de sua cidadania, o acesso aos locais públicos e privados, o acesso à informação e outras prerrogativas legais.

O Museu do Amanhã investiu muito nas escolhas dos materiais acessíveis que são de boa qualidade, mas a sinalização tátil necessita estar conforme a norma ABNT NBR 16537/2016 que garante uma sinalização clara e segura para as pessoas e para os visitantes com deficiência visual, proporcionando um Desenho Universal de qualidade, funcional e acessível.

No entendimento da norma ABNT NBR 16537/2016 a sinalização tátil permite a utilização intuitiva dos espaços focando em minimizar interpretações imprevistas, proporcionando segurança e uma mobilidade mais confortável para as pessoas com deficiência visual, isto é, entregar um ambiente mais acessível a todos. Não sendo recomendada a construção de uma sinalização tátil linear no solo com interrupções, tatear paredes, sinalização por contagem de passos, utilizar barreiras como guia de referência, desenho não padronizado da sinalização tátil, etc. É recomendado que todas as informações sobre direções e mobilidade estejam contidas na sinalização tátil.

De um modo geral, o áudio guia foi bem construído e demonstrou ser uma valiosa opção como Tecnologia Assistiva, mas o sistema que reproduz o áudio costuma entrar em conflito com o sistema operacional Android 
quando aciona, automaticamente, a proteção de tela comprometendo a usabilidade do sistema. Essa Tecnologia Assistiva contribuiu para a orientação e a mobilidade do usuário durante a visitação do Museu do Amanhã e em áudio descrever as maquetes táteis expostas. Em caso de conformidade com a norma ABNT NBR 106537/2016 e de mudanças necessárias no desenho da sinalização tátil, o áudio guia necessitará ser totalmente reformulado.

Os colaboradores que trabalham no museu demonstraram desconhecerem a importância da sinalização tátil, de mantê-la funcional e acessível às pessoas com deficiência visual. Essa evidência foi comprovada por numerosos obstáculos estarem sobre a sinalização tátil, por serem posicionados pelos próprios funcionários do museu e não presenciamos nenhuma iniciativa corretiva por partes deles em prol de manter a sinalização tátil operacional. Consideramos primordial que todos os colaboradores sejam orientados/treinados sobre a importância de se manter a sinalização tátil segura e acessível, além de tomarem conhecimento sobre os parâmetros cabíveis e disponíveis na norma da ABNT NBR 16537/2016.

Mediante as diversas análises, podemos inferir que o Museu do Amanhã está bem longe de cumprir uma de suas principais premissas “a acessibilidade” e necessita adequar-se as legislações vigentes destinadas às pessoas com deficiência e ao seu direito de ir e vir com segurança, sendo um grande passo a observância as normas da ABNT NBR 16537/2016, principalmente por se tratar de investimentos providos de recursos públicos e privados.

A promoção da acessibilidade requer conhecimento técnico e a devida aplicação do mesmo, sendo de grande valia que cada recurso seja testado e aprovado por seus maiores consumidores: as pessoas com deficiência, pois são elas que necessitam de recursos específicos que garantam mais independência e mobilidade para que desfrutem de um espaço confortável que possuam características de um desenho universal e que atenda a todos.

Tais erros foram apontados no intuito de não serem repetidos no futuro, pois esse cenário gera uma imagem negativa não somente para o Museu do Amanhã, mas para toda a sociedade. 


\section{REFERÊNCIAS}

ABNT, ASSOCIAÇÃO BRASILEIRA DE NORMAS TÉCNICAS (ABNT). NBR 16537: Acessibilidade Sinalização tátil no piso - Diretrizes para elaboração de projetos e instalação. 2016. Disponível em: <http:// www.pessoacomdeficiencia.gov.br/app/sites/default/files/arquivos/\%5Bfield_generico_imagens-filefielddescription\%5D_168.pdf>. Acesso em: 13 jan. 2017.

BAPTISTA, M. I. S. D. Convivendo com as diferenças. In: PUPO, Deise Tallarico (org.) et al. Acessibilidade: discurso e prática no cotidiano das bibliotecas. Campinas, SP: UNICAMP/Biblioteca Central Cesar Lattes, 2006. Cap. 2. p. 13-16.

BERSCH, Rita. Introdução à tecnologia assistiva. Porto Alegre, 2013. Disponível em: <http://www.assistiva. com.br/Introducao_Tecnologia_Assistiva.pdf>. Acesso em: 14 jan. 2016.

BRASIL, Constituição da Republica Federativa do Brasil. 1988. Disponível em: <http://www.planalto.gov.br/ ccivil_03/constituicao/constituicao.htm>. Acesso em: 13 jan. 2017.

BRASIL. Decreto 5.296 de 02 de dezembro de 2004. Regulamenta as Leis nos 10.048, de 8 de novembro de 2000, que dá prioridade de atendimento às pessoas que especifica, e 10.098, de 19 de dezembro de 2000, que estabelece normas gerais e critérios básicos para a promoção da acessibilidade das pessoas portadoras de deficiência ou com mobilidade reduzida, e dá outras providências. Disponível em: <http://www.planalto.gov.br/ ccivil_03/_ato2004-2006/2004/decreto/D5296.htm>. Acesso em: 12 jan. 2017.

BRASIL, Lei N 13.146 de 06 de Julho de 2015 que institui a Lei Brasileira de Inclusão da Pessoa com Deficiência Estatuto da Pessoa com Deficiência). Disponível em: < http://www.planalto.gov.br/ccivil_03/_ato20152018/2015/Lei/L13146.htm>. Acesso em: 12 jan. 2017.

GODINHO, Francisco. Novo conceito de acessibilidade? Janeiro, 2010. Disponível em: < http://www.inclusive. org.br/arquivos/13346>. Acesso em: 20 jan. 2017.

MUSEU, Museu do Amanhã. Site do Museu do Amanhã. Disponível em: < https://museudoamanha.org.br>. Acesso em: 12 jan. 2017.

SILVA JÚNIOR, Elias dos Santos; PINTO, S. C. C. S. ; BRAZ, RUTH MARIA MARIANI . A Internet das Coisas e a Plataforma Arduíno como Computação Embarcada em Mapas Táteis: Uma Avaliação dessa tecnologia Assistiva para o ensino das pessoas ouvintes com deficiência visual. 2018. Disponível em: <https://sucupira. capes.gov.br/sucupira/public/consultas/coleta/trabalhoConclusao/viewTrabalhoConclusao.jsf?popup=true\&id_ trabalho=7151041>. Acesso em $12 \mathrm{dez} .2018$. 